08

\title{
Кремний с магнитными нанокластерами атомов марганца - новый класс фотомагнитных материалов
}

\author{
(С) М.К. Бахадырханов, Х.М. Илиев, Г.Х. Мавлонов, К.С. Аюпов, С.Б. Исамов, С.А. Тачилин \\ Ташкентский государственный технический университет им. Ислама Каримова, \\ 100095 Ташкент, Узбекистан \\ e-mail: giyosiddin-m@rambler.ru
}

(Поступило в Редакцию 13 мая 2018 г.)

\begin{abstract}
Впервые установлена существенная фоточувствительность отрицательного магнитосопротивления (ОМС) в кремнии с магнитными нанокластерами атомов марганца при освещении как фоновым, так и ИКсветом (до $\lambda=3 \mu \mathrm{m}$ ) при комнатной температуре. Обнаружено, что освещение приводит к существенному уменьшению величины ОМС, т. е. наблюдается эффект гашения ОМС, а при более высокой интенсивности освещения происходит инверсия знака магнитосопротивления. Установлены закономерности изменения величины ОМС и условий инверсии знака магнитосопротивления.
\end{abstract}

DOI: 10.21883/JTF.2019.03.47179.184-18

\section{Введение}

Управление магнитными свойствами полупроводниковых материалов при помощи их освещения как фоновым светом, так и светом с определенной длиной волны, представляет большой научный и практический интерес. Прежде всего, это связано с возможностью создания принципиально нового класса фотомагнитных приборов, а также развития нового научного направления - фотоспинтроники. Как показывает анализ магнитных свойств существующих полупроводниковых материалов, легированных парамагнитными примесями, а также других магнитных материалов, магнитосопротивление в них практически не зависит от величины освещенности [1-3]. В этом плане кремний с магнитными нанокластерами атомов марганца является новым и очень перспективным фотомагнитным материалом.

\section{Теоретический анализ}

В работах [4-6] при исследовании состояния атомов марганца в кремнии методом электронного парамагнитного резонанса (ЭПР) было показано, что при определенных термодинамических условиях легирования эти примесные атомы создают нанокластеры, состоящие из четырех атомов марганца, находящихся в ближайших эквивалентных междоузельных положениях вокруг атомов бора в решетке кремния. Нами на основе разработанной технологии низкотемпературного диффузионного легирования [7] были определены оптимальные условия легирования, позволяющие обеспечить максимальное участие введенных примесных атомов в формирование нанокластеров по всему объему материала. Наличие нанокластеров в решетке кремния было многократно подтверждено проводимыми исследованиями с помощью методов ЭПР и атомной силовой микроскопии (АСМ), а также рентгеноструктурным анализом (рис. 1). Сверх- тонкие спектры ЭПР, состоящие из 21 линии (рис. 1, $a$ ) однозначно свидетельствуют о наличии нанокластеров, содержащих в своем составе четыре атома марганца $(\mathrm{Mn})_{4}$. Эти результаты являются прямым доказательством образования магнитных кластеров примесных атомов в решетке кремния [8-10]. Примесные атомы марганца являются парамагнитными центрами со спином $S=5 / 2\left(3 d^{5} 4 s^{0}\right)$, и в зависимости от условий легирования могут находиться в кристаллической решетке кремния в состояниях $\mathrm{Mn}^{0}\left(3 d^{5} 4 s^{2}\right), \mathrm{Mn}^{+}\left(3 d^{5} 4 s^{1}\right)$, $\mathrm{Mn}^{++}\left(3 d^{5} 4 s^{0}\right)$ или $[\mathrm{MnB}]^{+}$.

Если учесть, что атомы марганца в кремнии создают два донорных энергетических уровня $E_{1}=E_{C}-0.27 \mathrm{eV}$ и $E_{2}=E_{C}-0.5 \mathrm{eV}[11]$, то в компенсированных образцах $p$-Si $\langle\mathrm{B}, \mathrm{Mn}\rangle$ с $\rho=(5-10) \cdot 10^{3} \Omega \cdot \mathrm{cm}$, в которых энергия Ферми равна $E_{F}=E_{V}+(0.38-0.45) \mathrm{eV}$, все введенные атомы марганца в основном находятся в двукратно положительно ионизованном состоянии $\mathrm{Mn}^{++}$.

Эти данные дают полное основание считать, что основная часть нанокластеров имеет мощный магнитный момент со спином $\left(S_{(\mathrm{Mn}) 4}=4 \cdot \frac{5}{2}=10\right)$ и максимальную кратность заряда, т.е. $\left[(\mathrm{Mn})_{n}^{+8} \mathrm{~B}^{-1}\right]^{+7}$ и $\left[(\mathrm{Mn})_{n}^{+7} \mathrm{~B}^{-1}\right]^{+6}$, но появление обратного магнитосопротивления (OMC) и его величина связаны с одновременным изменением мощного магнитного момента и зарядового состояния нанокластеров.

В работах $[9,12]$ было установлено, что образцы кремния с магнитными нанокластерами атомов марганца, полученные по новой технологии, обладают большей фоточувствительностью, чем компенсированный кремний, легированный марганцем по обычной технологии [13].

\section{Экспериментальная часть}

Для получения образцов кремния с магнитными нанокластерами по разработанной нами низкотемпературной поэтапной диффузии был использован монокристалличе- 
ский кремний $p$-типа проводимости с удельным сопротивлением $\rho=3 \Omega \cdot \mathrm{cm}$.

Сущность нового способа легирования заключается в проведении диффузии поэтапно с определенной скоростью повышения температуры. Показано, что этот способ не только позволяет осуществить максимальное участие введенных атомов в формировании нанокластеров, но также обеспечивает равномерное распределение магнитных нанокластеров по всему объему материала. Это дает полное основание считать, что экспериментальные величины энергии активации диффузии и
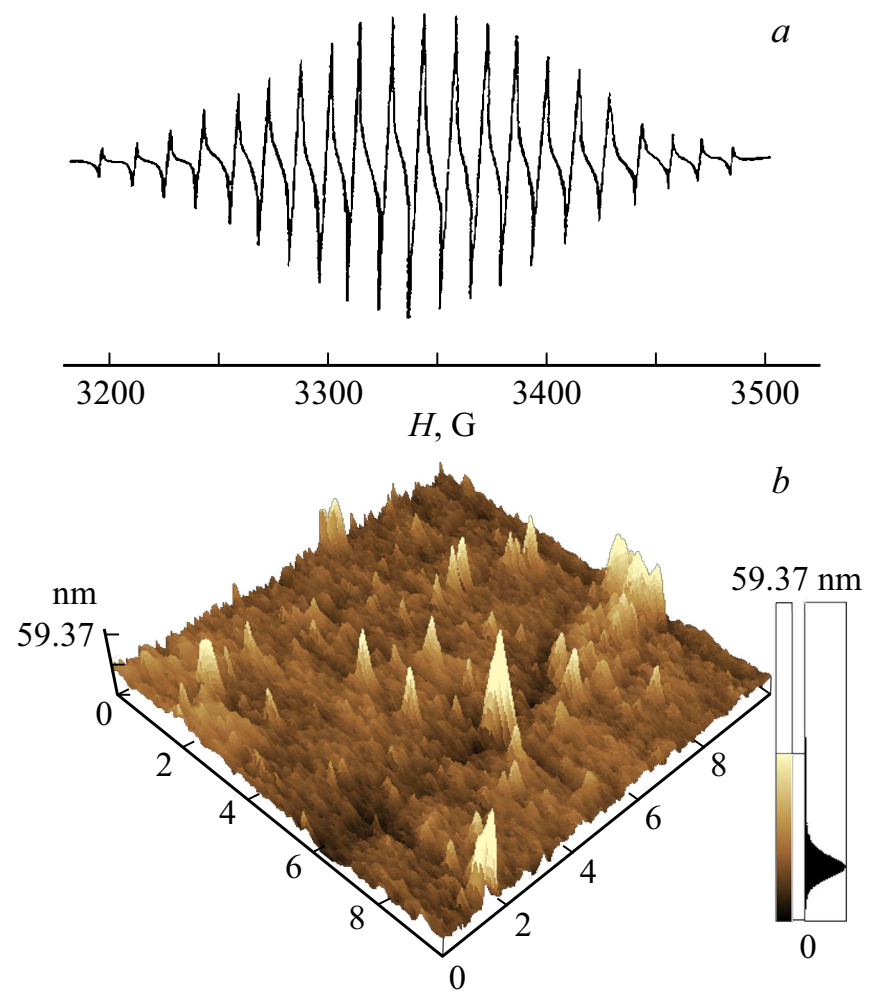

$10.00 \times 10.00 \mu \mathrm{m} Z 0.00-59.37 \mathrm{~nm}$ foreign

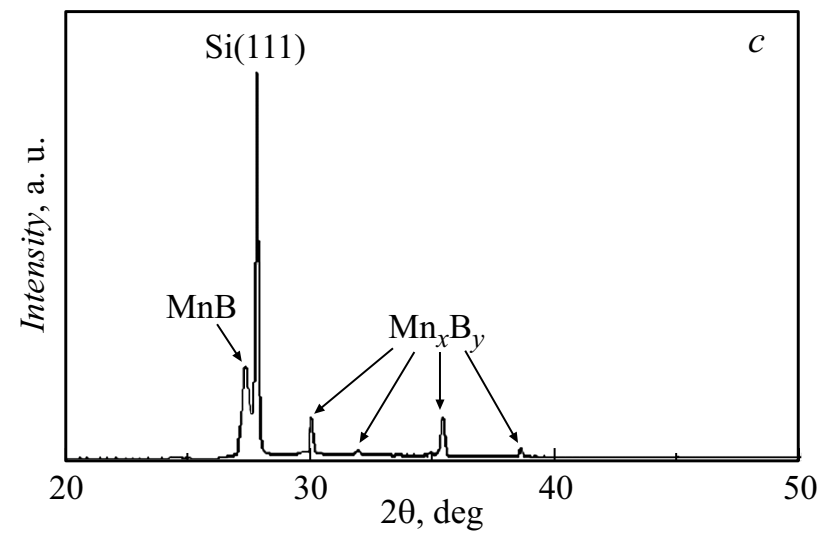

Рис. 1. $a-$ спектр ЭПР-нанокластера, состоящий из четырех атомов марганца в кремнии; $b-$ изображение нанокластеров примесных атомов марганца в кремнии, полученное на силовом атомном микроскопе; $c-$ рентгенографическое изображение магнитных кластеров. соответственно температурную зависимость диффузии $D=D_{0} \exp \left(-\frac{E_{0}}{k T}\right)$, а также растворимость примесей, полученных на основе высокотемпературной диффузии, нельзя использовать в условиях низкотемпературной диффузии, а процесс диффузии при этом существенно ускоряется, что полностью подтверждает предположение о вынужденной диффузии примесных атомов по междоузлиям.

После проведенной диффузии, управляя условиями легирования, был получен кремний с удельным сопротивлением $p=10^{3}-4 \cdot 10^{4} \Omega \cdot \mathrm{cm} p$-типа проводимости при $T=300 \mathrm{~K}$.

Для исследования влияния фонового света на величину и характер ОМС в исследуемых образцах была создана специальная установка, позволяющая регулировать в широком диапазоне интенсивность освещения, величину магнитного и электрического полей, а также температуру.

Исследование влияния ИК-света на ОМС в образцах проводилось на установке ИКС-21. Для предотвращения попадания фонового света в окошке криостата был установлен фильтр из полированного кремния толщиной $400 \mu \mathrm{m}$. При этом мощность излучения в исследуемом интервале спектра поддерживалась постоянной на уровне $10^{-5} \mathrm{~W} / \mathrm{cm}$.

\section{Результаты и их обсуждения}

Результаты исследования показали, что в полученных образцах при комнатной температуре наблюдается достаточно высокое ОМС, величина ОМС в этих образцах существенно зависит от их электрических параметров независимо от величины магнитного поля, и во всех случаях наблюдается линейный характер зависимости ОМС от величины магнитного поля (рис. 2). Эти результаты показывают, что, управляя электрическими параметрами образцов, можно в широком интервале варьировать ОМС. Как видно, аномально высокие величины ОМС наблюдаются в образцах с $\rho=(5-7) \cdot 10^{3} \Omega \cdot \mathrm{cm}$.

На рис. 3 представлена зависимость различных величин ОМС в полученных образцах от интенсивности фонового освещения. Эти результаты показывают, что освещение приводит к уменьшению величины ОМС, т.е. практически наблюдается эффект гашения ОМС фоновым светом. Как видно, в образцах с максимальной величиной ОМС (кривая 2) с ростом интенсивности освещения $(I)$ величина ОМС существенно уменьшается, а при $I=801 \mathrm{x}$ происходит инверсия знака магнитосопротивления - переход от ОМС к положительному магнитосопротивлению (ПМС), величина которого достаточно низка $\left(\frac{\Delta \rho}{\rho}=5-7 \%\right)$, и оно практически не зависит от освещения. Таким образом, в интервале $I=0-801 \mathrm{x}$ величина ОМС уменьшается от 100 до нуля. Это показывает, что кремний с магнитными нанокластерами обладает уникальными свойствами, которые позволяют управлять магнитными свойствами этого матери- 


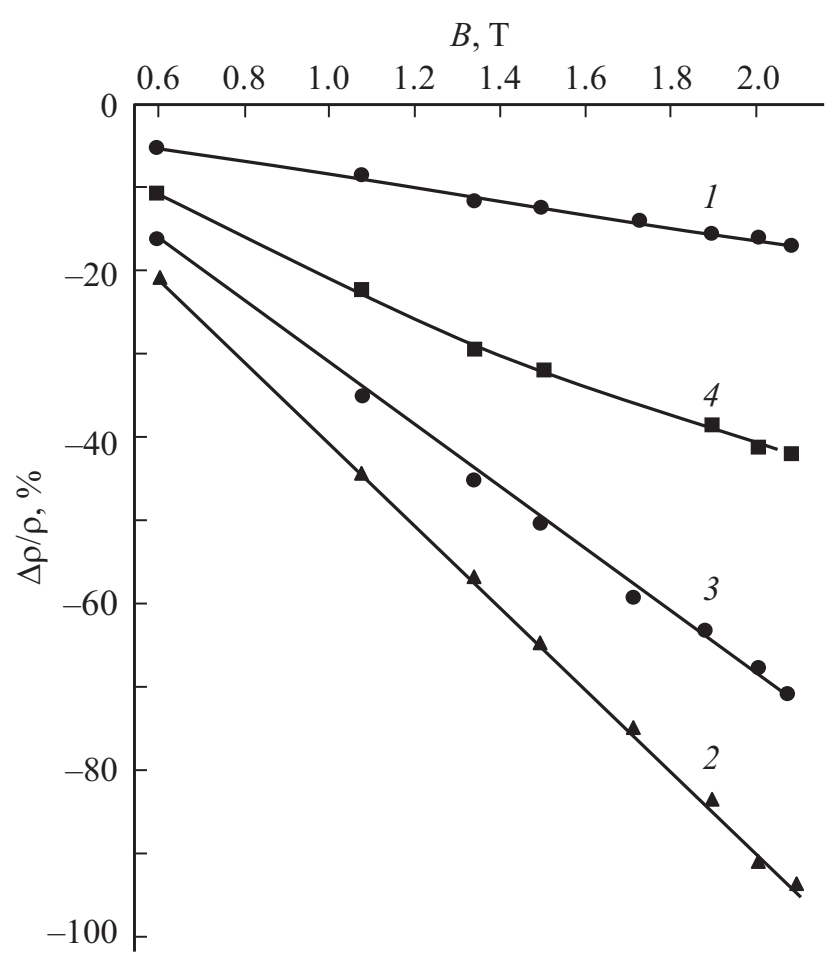

Рис. 2. Зависимость магнитосопротивления от магнитного поля в образцах $p$-типа с нанокластерами при $T=300 \mathrm{~K}$ : $1-\rho=8 \cdot 10^{2} \Omega \cdot \mathrm{cm} ; 2-\rho=7 \cdot 10^{3} \Omega \cdot \mathrm{cm} ; 3-$ $\rho=2 \cdot 10^{4} \Omega \cdot \mathrm{cm} ; 4-\rho=4 \cdot 10^{4} \Omega \cdot \mathrm{cm}$.

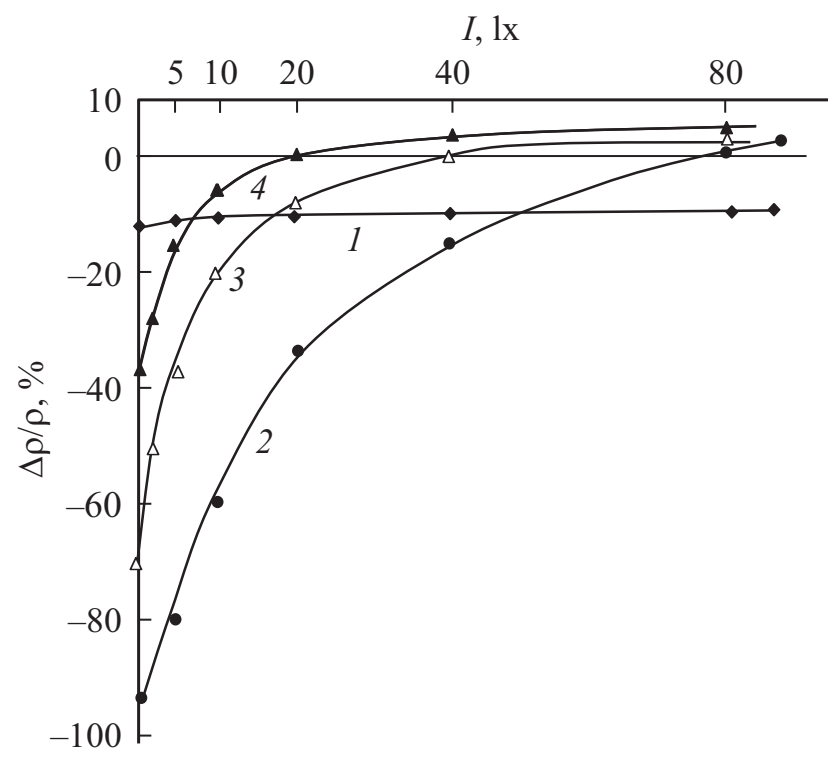

Рис. 3. Зависимость магнитосопротивления от интенсивности освещения в образцах $\mathrm{Si}\langle\mathrm{B}, \mathrm{Mn}\rangle$-типа с различным удельным сопротивлением: $1-\rho=8 \cdot 10^{2} \Omega \cdot \mathrm{cm}$; $2-\rho=7 \cdot 10^{3} \Omega \cdot \mathrm{cm} ; 3-\rho=2 \cdot 10^{4} \Omega \cdot \mathrm{cm} ; 4-$ $\rho=4 \cdot 10^{4} \Omega \cdot \mathrm{cm}$ при $T=300 \mathrm{~K}$.

ала при помощи фонового освещения. С уменьшением начальной величины ОМС в образцах характер его изменения от интенсивности освещения сохраняется, но величина интенсивности освещения, при которой происходит инверсия знака магнитосопротивления, сдвигается в сторону меньших величин (кривые 3,4). В образцах с величиной ОМС меньше $15 \%$ влияние освещения на ОМС практически отсутствует (кривая 1).

Таким образом, эти результаты показывают, что при помощи освещения можно в широком интервале управлять не только магнитными свойствами кремния, но и инверсией знака магнитосопротивления и величиной ОМС в образцах.

Очень интересные результаты были получены при исследовании температурной зависимости ОМС в образцах при различных интенсивностях освещения (рис. 4). Как видно, с понижением температуры $(T<300 \mathrm{~K})$ величина ОМС существенно увеличивается и достигает своего максимального значения при $T=240-250 \mathrm{~K} \quad\left(\frac{\Delta \rho}{\rho}=300 \%\right)$. Дальнейшее снижение температуры приводит к быстрому уменьшению ОМС, а при $T=170-175 \mathrm{~K}$ происходит инверсия знака магнитосопротивления, т. е. ОМС переходит в ПМС, величина которого слабо зависит от температуры (кривая 1). Эти результаты показывают еще одну особенность ОМС в кремнии с магнитными нанокластерами, отличающую данный материал от других магнитных полупроводников, где имеет место монотонное увеличение величины OMC с понижением температуры $[14,15]$.

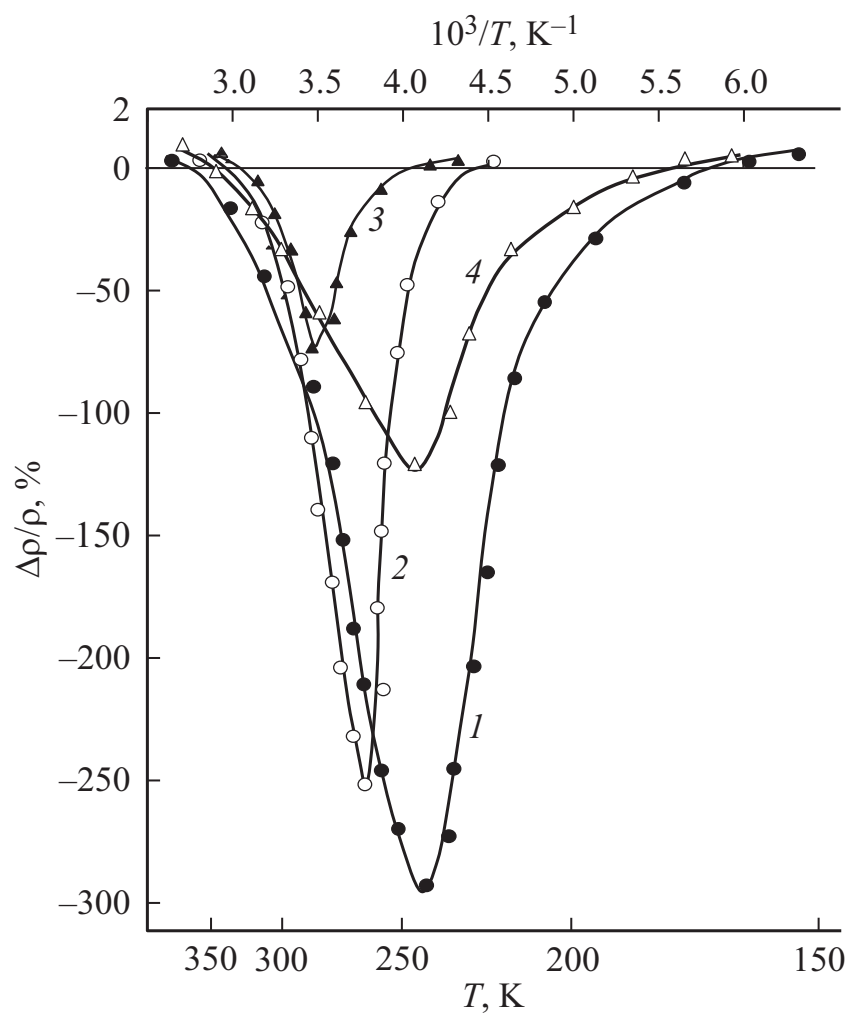

Рис. 4. Зависимости магнитосопротивления от температуры в образцах $\mathrm{S}\langle\mathrm{B}, \mathrm{Mn}\rangle$ с $\rho=7 \cdot 10^{3} \Omega \cdot \mathrm{cm}: 1-$ темновая; $2-$ $I=101 \mathrm{x} ; 3-I=401 \mathrm{x}$ при $B=2 \mathrm{~T} ; 4-$ темновая при $B=1 \mathrm{~T}$. 


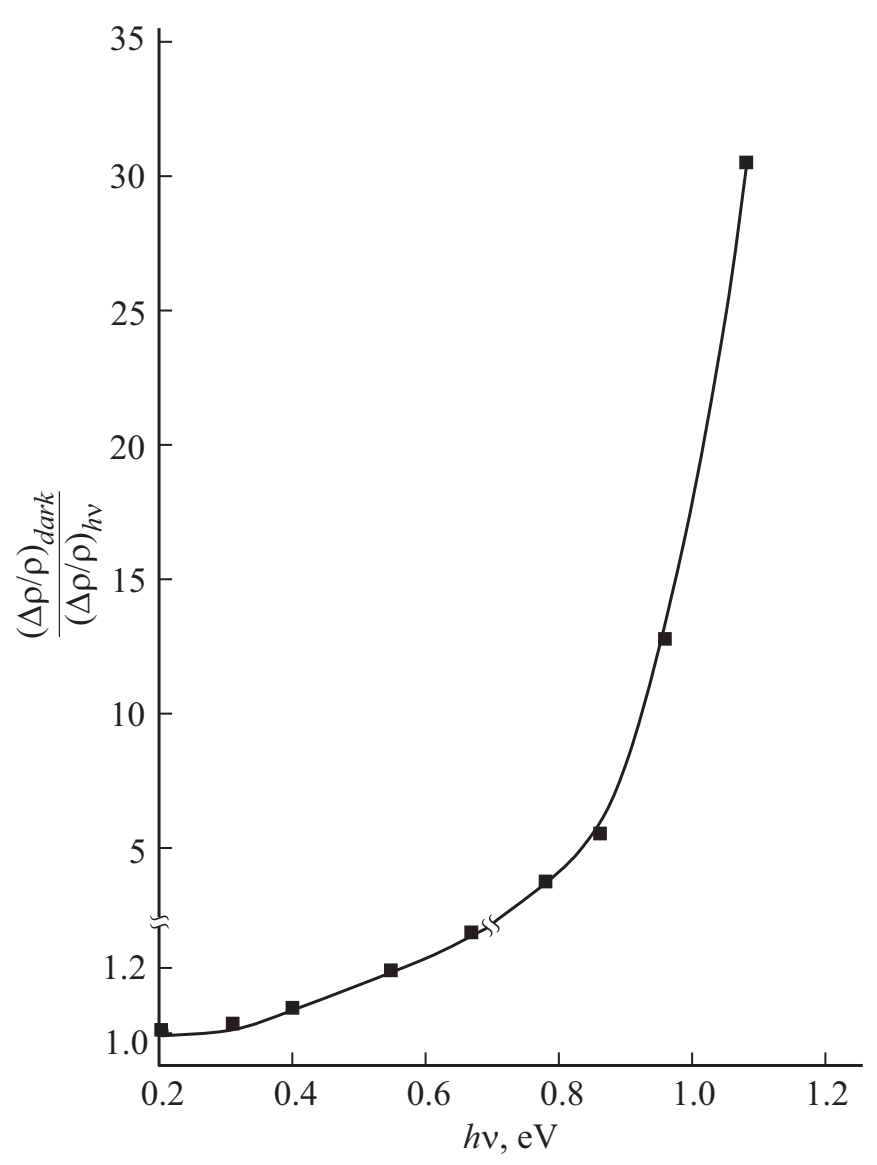

Рис. 5. Спектральная зависимость кратности уменьшения ОМС под действием ИК-света $\left(\frac{\Delta \rho}{\rho}\right)_{h v}$ относительно темнового значения $\mathrm{OMC}\left(\frac{\Delta \rho}{\rho}\right)_{d a r k}$ в образцах $\mathrm{Si}\langle\mathrm{B}, \mathrm{Mn}\rangle$-типа с $\rho=7 \cdot 10^{3} \Omega \cdot \mathrm{cm}$.

Температурный ход ОМС в образцах при их освещении приводит к следующим интересным явлениям. Первое - эффект гашения ОМС после освещения образцов сохраняется при всех исследуемых температурах. Второе - существенное смещение температуры в сторону более низких величин, при которых наблюдается максимальное ОМС. Третье - существенно сужается температурная область существования ОМС. Четвертое - наблюдается двойная инверсия знака магнитосопротивления как при высоких, так и при низких температурах (кривые 2-4).

Таким образом, можно утверждать, что одновременное действие температуры и освещения достаточно низкой интенсивности существенно расширяет функциональные возможности использования кремния с магнитными нанокластерами в электронике.

Результаты исследования показали, что влияние ИКсвета на ОМС начинается при $h v=0.4 \mathrm{eV}(\lambda=3 \mu \mathrm{m})$. Установлено, что при этом, как и в случае фонового света, величина ОМС уменьшается при освещении ИКсветом, т. е. имеет место ИК-гашение ОМС. Кратность гашения ОMC

$$
k=\left[\left(\frac{\Delta \rho}{\rho}\right)_{d a r k} /\left(\frac{\Delta \rho}{\rho}\right)_{h \nu}\right]
$$

(где $\left(\frac{\Delta \rho}{\rho}\right)_{h v}$ - ОМС при освещении образцов ИКсветом с энергией $h v$, a $\left(\frac{\Delta \rho}{\rho}\right)_{d a r k}-$ ОМС образцов, когда ИК-излучение отсутствует) существенно увеличивается с ростом энергии падающих фотонов (рис. 5). При $h v=1 \mathrm{eV}$ ОМС уменьшается примерно в 35 раз при мощности ИК-излучения $10^{-5} \mathrm{~W} / \mathrm{cm}$. Таким образом, впервые показана существенная спектральная чувствительность магнитосопротивления в полупроводнике, т.е. в кремнии с магнитными нанокластерами.

\section{Заключение}

Полученные экспериментальные данные показывают, насколько перспективно формирование магнитных нанокластеров на основе парамагнитных примесных атомов в кристаллической решетке кремния. В результате исследования установлено, что увеличение концентрации магнитных нанокластеров в кристаллической решетке кремния существенно усиливает наблюдаемые эффекты и расширяет область их существования как при фоновом освещении, так и в ИК-области спектра. При этом следует отметить, что наблюдаемые фотомагнитные явления имеют место только в образцах с магнитными нанокластерами. В образцах, где атомы марганца не формируют магнитные нанокластеры, представленные фотомагнитные явления отсутствуют, в данном материале наблюдается только слабое ПМС.

Можно сделать вывод, что формирование магнитных нанокластеров атомов марганца в кремнии не только выявляет аномально большое ОМС при комнатной температуре, но и раскрывает еще не известные грани магнитных нанокластеров - магнитных квантовых точек, свойства которых только начинают исследовать, а кремний с магнитными нанокластерами атомов марганца является новым перспективным фотомагнитным материалом, обладающим уникальными функциональными возможностями и физическими свойствами.

\section{Список литературы}

[1] Солин Н.И., Ромашев Л.Н., Наумов С.В., Саранин А.А., Зотов А.В., Олянич Д.А., Котляр В.Г., Утас О.А. // ЖТФ. 2016. Т. 86. Вып. 2. С. 78-84.

[2] Аронзон Б.А., Драченко А.Н., Рыльков В.В., Леотин Ж. // ФТП. 2006. Т. 40. Вып. 7. С. 819-823.

[3] Воронина Т.И., Лагунова Т.С., Михайлова М.П., Моисеев К.Д., Липаев А.Ф., Яковлев Ю.П. // ФТП. 2006. Т. 40. Вып. 5. С. 519-535.

[4] Ludwig G.W., Woodbury H.H., Carlson R.O. // J. Phys. Chem. Sol. 1959. Vol. 8. P. 490. 
[5] Фистуль В.И., Казакова В.М., Бобриков Ю.А., Рябцев А.В., Абдурахманов К.П., Зайнабидинов С., Камилов Т.С., Утамурадова Ш.Б. // ФТП. 1982. Т. 16. Вып. 5. C. 939-941.

[6] Kreissl J., Gehlhoff W. // Phys. Stat. Sol. B. 1988. Vol. 145. P. 609-616.

[7] Бахадырханов М.К., Аюпов К.С., Илиев Х.М., Мавлонов Г.Х., Саттаров О.Э. // Письма в ЖТФ. 2010. Т. 36. Вып. 16. С. 11-18.

[8] Бахадырханов М.К., Мавлонов Г.Х., Исамов С.Б., Илиев Х.М., Аюпов К.С., Сапарниязова З.М., Тачилин С.А. // Неорган. материалы. 2011. Т. 47. № 5. С. 545-550.

[9] Бахадырханов М.К., Аюпов К.С., Мавлянов Г.Х., Илиев Х.М., Исамов С.Б. // Микроэлектроника. 2010. Т. 39. № 6. C. 426-429.

[10] Yunusov Z.A., Yuldashev Sh.U., Igamberdiev Kh.T., Kwon Y.H., Kang T.W., Bakhadyrkhanov M.K., Isamov S.B., Zikrillaev N.F. // J. Korean Phys. Society. 2014. Vol. 64. N 10. P. 1461-1465.

[11] Абдурахманов К.П., Лебедев А.А., Крейсль Й., Утамурадова Ш.Б. // ФТП. 1985. Т. 19. Вып. 2. С. 213-216.

[12] Bakhadyrkhanov M.K., Isamov S.B. // Appl. Sol. Energ. 2014. Vol. 50. N 2. P. 61-63.

[13] Болтакс Б.И. Диффузия и точечные дефекты в полупроводниках. Л.: Наука, 1972. 384 с.

[14] Бойков Ю.А., Клаесон Т. // ФТТ. 2005. Т. 47. Вып. 2. С. 274 280.

[15] Лагунова Т.С., Воронина Т.И., Михайлова М.П., Моисеев К.Д., Самохин Е., Яковлев Ю.П. // ФТП. 2003. Т. 37. Вып. 8. С. 905-911. 